\title{
Analysis of Adhesion between Wet Clay Soil and Rotary Tillage Part in Paddy Field Based on Discrete Element Method
}

\author{
Jian Cheng ${ }^{1,2}$, Kan Zheng 1,2,*, Junfang Xia ${ }^{1,2}$, Guoyang Liu ${ }^{1,2}$, Liu Jiang 1,2 and Dong Li 1,2 \\ 1 College of Engineering, Huazhong Agricultural University, Wuhan 430070, China; \\ chengjiancj@webmail.hzau.edu.cn (J.C.); xjf@mail.hzau.edu.cn (J.X.); lgy@webmail.hzau.edu.cn (G.L.); \\ 2020307120027@webmail.hzau.edu.cn (L.J.); Li_dong@webmail.hzau.edu.cn (D.L.) \\ 2 Key Laboratory of Agricultural Equipment in Mid-Lower Yangtze River, Ministry of Agriculture and Rural \\ Affairs, Wuhan 430070, China \\ * Correspondence: zhengkan@mail.hzau.edu.cn; Tel.: +86-152-7189-0761
}

check for updates

Citation: Cheng, J.; Zheng, K.; Xia, J.; Liu, G.; Jiang, L.; Li, D. Analysis of Adhesion between Wet Clay Soil and Rotary Tillage Part in Paddy Field Based on Discrete Element Method Processes 2021, 9, 845. https:// doi.org/10.3390/pr9050845

Academic Editor: Joanna Wiącek

Received: 15 April 2021

Accepted: 10 May 2021

Published: 12 May 2021

Publisher's Note: MDPI stays neutral with regard to jurisdictional claims in published maps and institutional affiliations.

Copyright: (c) 2021 by the authors. Licensee MDPI, Basel, Switzerland. This article is an open access article distributed under the terms and conditions of the Creative Commons Attribution (CC BY) license (https:// creativecommons.org/licenses/by/ $4.0 /)$

\begin{abstract}
To analyze the process of wet clay soil adhering to the rotary tillage part during rotary tillage in paddy field, simulation tests were carried out based on the discrete element method (DEM) in this study. The Plackett-Burman (PB) test was applied to obtain simulation parameters that significantly affected the soil adhesion mass. The Box-Behnken design (BBD) based on the principle of response surface method (RSM) was used to establish a regression model between significant parameters and soil adhesion mass. The soil adhesion mass obtained from the actual soil bin test as the response value was brought into the regression model. The optimal simulation parameters were obtained: the particle-particle coefficient of rolling friction, the particle-geometry coefficient of static friction, and the particle-particle JKR (Johnson-Kendall-Roberts) surface energy were 0.09, 0.81, and $61.55 \mathrm{~J} \cdot \mathrm{m}^{-2}$, respectively. The reliability of the parameters was verified by comparing the soil adhesion mass obtained under the optimal simulation parameters with the actual test value, and the relative error was $1.84 \%$. Analysis of the rotary tillage showed that soil adhesion was mainly concentrated in the sidelong section of the rotary blade. The maximum number of upper soil particles adhering to the rotary tillage part was 2605 compared to the middle soil and lower soil layers. The longer the distance the rotary tillage part was operated in the soil for, the more soil particles would adhere to it. This study can provide a reference for the rational selection of simulation parameters for rotary tillage and the analysis of soil adhesion process in rotary tillage.
\end{abstract}

Keywords: discrete element method; process analysis; rotary tillage; wet clay soil; soil adhesion

\section{Introduction}

Rotary tillage improves the physical properties of the soil and the growing conditions of the crop, and is an important basic process to meet the requirements of seedbed preparation and planting [1]. The middle and lower reaches of the Yangtze River agricultural region are mainly in the rice-rape and rice-wheat water-dry rotation cropping patterns. The straw residues of the crop will be buried in the soil between the double-cropping rotation gaps. Large amounts of straw create more pore space in the soil, reducing soil bulk, increasing soil carbon content, and improving nitrogen utilization and use efficiency [2]. During the rice growing stage, flooding and poor air permeability increased soil bulk density, compaction, and moisture content [3]. Soil textures include silty clay, loam, silty clay loam, and silty loam. Long-term irrigation, drainage, and tillage causes paddy soil to be sticky, have high plasticity, and absorb water easily [4,5]. Due to these characteristics of wet clay soil, during field operations, the soil is squeezed and cut using a tillage machine, causing the surface of the machine to adhere to the soil, which will reduce the quality of the operation [6]. Studies have shown that soil adhesion can increase the cutting resistance of machine by $30 \%$ and fuel consumption by $30 \%$ to $50 \%$ [7]. Soil adhesion is more pronounced during the rotary tillage. It is difficult to study the adhesion of wet clay soil to the 
rotary tillage part only from field experiments because of the limitation of tillage season and soil adhesion measurement difficulties.

The main reason for soil adhesion is considered to be the presence of a soil water film that adheres the soil to the surface of the object [8]. In order to reduce the effect of soil adhesion on fieldwork machinery, Massah et al. found that applying higher voltages and prolonged currents to the plate by using the bionic electroosmotic technique reduced soil adhesion [9]. Zhang et al. designed an extraction device for collecting earthworm mucus. The rheological properties of mucus samples were analyzed to explain the mechanism of viscosity reduction and provide a basis for reducing soil adhesion mechanisms [10]. Araya et al. and Schafe et al. investigated the effect of airflow, water and aqueous polymer solutions on soil adhesion [11,12].

Soil-tool numerical simulations will contribute to a better understanding of soil-soil and soil-tool interactions $[13,14]$. The operation of the machine in the field will lead to the interaction between the machine and the soil, and the soil particles and particles will collide with each other, all of which will generate force. Simulation of force transfer in a collection of particles was done using the discrete element method. Ucgul et al. investigated the plastic deformation of soil particles with and without bonding and the stacking angle and penetration test were used to determine the simulation parameters, which provided a reference for the selection of a soil contact model [15]. Wang et al. evaluated particles of different radius sizes to simulate soil-tool interactions to explore the effect of particle size on soil-tool interactions and soil disturbance [16]. There are also studies discussing the discrete element method to explore the variation law of soil stress, velocity and soil displacement in the subsoil, simulating the disturbance behavior of the deep soil. The disturbance range of the soil at different depths and the variation law of the force on the particles were obtained [17-19]. The above studies focus on the analysis of soil morphology and microdisturbance and the evaluation of post-tillage mechanical indicators. The contact model between the deep tillage tool and the soil is relatively mature, but there are characteristics such as large soil disturbance and high soil viscosity when the rotary tillage part is operated in wet clay soil. Therefore, these tillage models are not applicable to the analysis of the dynamics of rotary tillage part.

For the rotary tillage, domestic and foreign research mainly focuses on the design and optimization of the structural parameters of the rotary tillage part, which can achieve energy saving and consumption reduction. Matin et al. analyzed the effect of the three geometries of rotary blades on operating power consumption at four different rotational speeds, and the results showed that the power of different shapes of rotary blade increased as the rotational speed increased, and the straight blade consumed the least power. The effect of three different bending degrees of rotary blades on tillage at three tillage depths and two different mounting positions was further investigated [20,21]. Sun et al. developed a bionic tillage component based on the characteristic of low resistance of brown bear claws using a discrete element model of red soil, and used the response surface method to find the optimal tillage parameters to obtain a bionic trenching blade with low resistance [22]. However, the phenomenon of soil adhesion hindering productivity during rotary tillage in wet clay soil is always present.

The objective of this study is to construct a soil adhesion mass prediction model of wet clay soil and rotary tillage part in the paddy field to obtain simulation parameters and analyze the soil adhesion process using the DEM to provide a theoretical basis for rotary tillage to reduce soil adhesion.

\section{Materials and Methods}

\subsection{Test Materials}

The test soil was obtained from the experimental farm of Institute of Grain Crops, Hubei Provincial Academy of Agricultural Sciences $\left(114^{\circ} 18^{\prime}\right.$ E, $\left.30^{\circ} 29^{\prime} \mathrm{N}\right)$. The test soil was wet clay soil in a paddy field, and the field was in a perennial water-dry rotation (rice-rape, rice-wheat). More water was retained in clay soil. Drainage and drying of the field before 
harvest, the moisture content of the soil in the test area ranged from $33.24 \%$ to $38.02 \%$ at a depth of $0 \sim 200 \mathrm{~mm}$. The average value of compactness was $296 \mathrm{kPa}$. Soil bulk density, moisture content, and organic matter content were measured by the cutting ring method, drying method, and potassium dichromate external heating method, respectively. Soil particle size was determined by an electric vibrating screen. The basic physical properties of the soil were shown in Table 1.

Table 1. The basic physical properties of the soil.

\begin{tabular}{|c|c|c|c|c|c|c|c|c|}
\hline \multicolumn{2}{|c|}{ Bulk Density/(g.cm $\left.{ }^{-3}\right)$} & \multicolumn{2}{|c|}{ Moisture Content $/ \%$} & \multicolumn{2}{|c|}{$\begin{array}{c}\text { Organic Matter } \\
\text { Content } /\left(\mathrm{g} \cdot \mathrm{kg}^{-1}\right)\end{array}$} & \multicolumn{3}{|c|}{ Particle Composition/\% } \\
\hline $\begin{array}{l}\text { Average } \\
\text { Value }\end{array}$ & $\begin{array}{l}\text { Standard } \\
\text { Deviation }\end{array}$ & $\begin{array}{l}\text { Average } \\
\text { Value }\end{array}$ & $\begin{array}{l}\text { Standard } \\
\text { Deviation }\end{array}$ & $\begin{array}{l}\text { Average } \\
\text { Value }\end{array}$ & $\begin{array}{l}\text { Standard } \\
\text { Deviation }\end{array}$ & $\begin{array}{c}\text { Clay } \\
<0.002 \mathrm{~mm}\end{array}$ & $\begin{array}{c}\text { Silt } \\
0.05 \sim 2.0 \mathrm{~mm}\end{array}$ & $\begin{array}{c}\text { Sand } \\
0.05 \sim 2.0 \mathrm{~mm}\end{array}$ \\
\hline 1.15 & 0.15 & 35.75 & 1.35 & 15.26 & 2.34 & 42.46 & 49.29 & 8.25 \\
\hline
\end{tabular}

As shown in Figure 1, the soil adhesion test of the rotary tillage part was conducted using the rotary tillage part performance test bench designed by our group [23]. The test bench consisted of a track system and test vehicle, where the test vehicle included a rotary tillage part, tillage depth adjustment part, pressing roller, and control box. The track system was laid on the outdoor farm ground to simulate the function of a soil bin. The test vehicle used self-driven travel along the track, and could achieve $0 \sim 1.17 \mathrm{~m} \cdot \mathrm{s}^{-1}$ forward speed, 0 340 rpm rotational speed of tillage and 0 300 mm tillage depth with stable stepless adjustment. In this way, it will avoid the problem of field tests where the interaction between the tractor wheels and the soil caused the soil to sink and changed in the physical properties of the soil [24]. The test soil was filled into the soil bin, and the soil was leveled and compacted using a pressing roller. Soil compactness error was $\pm 5 \mathrm{kPa}$. The soil physical properties of the soil bin test were ensured to be basically the same in the field.

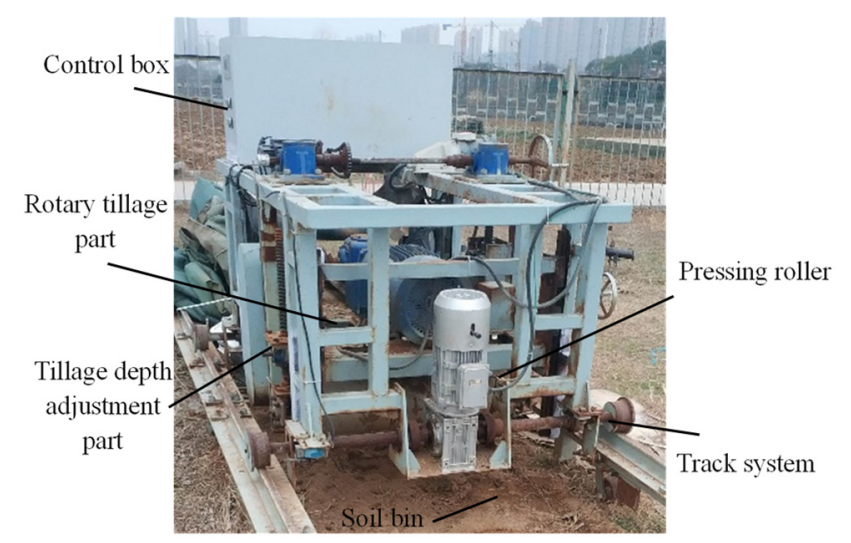

Figure 1. Test bench.

As shown in Figure 2, the rotary tillage part was commonly used for rotary tillage in the middle and lower reaches of the Yangtze River. Total length of the rotary tillage part was $680 \mathrm{~mm}$ and the material was $65 \mathrm{Mn}$. The center distance between the blade holder was $60 \mathrm{~mm}$. The distance between the two blade holders in the axial direction was $60 \mathrm{~mm}$. There were two blade holders and two rotary blades on the same cross section as one rotary tillage unit. There were 7 rotary tillage units on the rotary tillage part. In the axial direction, the phase angle between two rotary blades on the same cross section was $135^{\circ}$, and the angle of the adjacent two rotary blades was $51^{\circ}$. The rotary blade adopted the Chinese standard model IT245, which had a rotation radius of $245 \mathrm{~mm}$. The blade holder and the rotor shaft were welded to each other, and the rotary blade and the blade holder were bolted together. The rotary tillage part was attached to the test vehicle by bolts and nuts. Rotary tillage part was manufactured by ourselves in the engineering base of 
Huazhong Agricultural University. The soil bin test was repeated five times at a tillage depth of $150 \mathrm{~mm}$, a forward speed of $600 \mathrm{~m} \cdot \mathrm{s}^{-1}$ and a rotation speed of $150 \mathrm{rpm}$. The soil adhesion mass on the rotary tillage part after the tests were measured by means of an electronic scale (accuracy $\pm 0.01 \mathrm{~g}$ ).

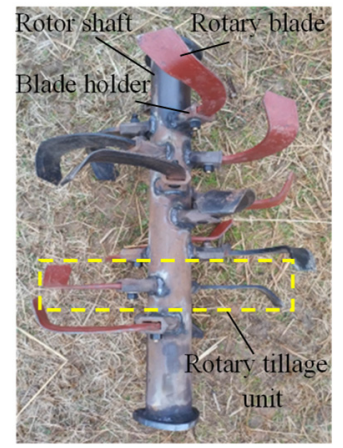

(a)

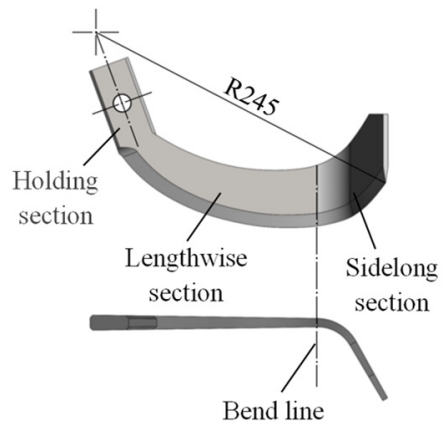

(b)

Figure 2. Rotary tillage part: (a) overall structure of rotary tillage part; (b) rotary blade.

\subsection{Theoretical Model}

The cohesion and plastic properties of wet clay soil in the middle and lower reaches of Yangtze River are much greater than the elastic properties between soil in their macroscopic expression. Large agglomerates are produced due to the high cohesion between soil particles. The Hertz-Mindlin with JKR (Johnson-Kendall-Roberts) contact model is a cohesive particle contact model based on the Hertz theory. The JKR contact model takes into account the effects of van der Waals force in the contact area and allows the user to simulate systems with strong viscosity. The JKR model will provide cohesive forces of mutual attraction between particles, even if there is no contact between particles within a certain gap. Therefore, the JKR model is suitable for simulating materials with particle-particle adhesion and agglomeration due to electrostatic forces, moisture, etc. When the machine is working in the field, the soil is cut and squeezed, and adhesion is created between the soiltouching parts and the soil surface. The Linear cohesion model corrects the Hertz-Mindlin contact by adding a normal cohesion. For the above characteristics, the Hertz-Mindlin with JKR contact model was selected as the particle-particle contact model. Linear cohesion contact model was adopted as the contact model between particle-geometry.

Both the Hertz-Mindlin JKR with the contact model and the Linear cohesion contact model are based on the soft-sphere model in EDEM. In Figure 3, the dashed line indicates the original particle position at the beginning of contact. As the particle is squeezed to produce relative movement, the surface of the particle is gradually deformed in the process of contact with other particles and geometry to produce contact force. The contact forces are obtained by calculating the normal overlap $i$ and the tangential displacement $j$.

Johnson et al. showed that the normal elastic contact force $F_{\mathrm{JKR}}$ for the JKR contact model could be calculated, which is given as follow Equation (1) [25]:

$$
F_{\mathrm{JKR}}=-4 \sqrt{\pi \cdot \gamma \cdot E^{*}} \alpha^{\frac{3}{2}}+\frac{4 E^{*}}{3 R^{*}} \alpha^{3} .
$$

The relationship between the contact radius $\alpha$ and the overlap between particles $\delta$ is as follow Equation (2):

$$
\delta=\frac{\alpha^{2}}{R^{*}}-\sqrt{\frac{4 \pi \gamma \alpha}{E^{*}}}
$$

where, $F_{\mathrm{JKR}}$ is the JKR normal force, $\mathrm{N} ; \gamma$ is the surface energy, $\mathrm{N} / \mathrm{m} ; E^{*}$ is the equivalent elastic modulus, $\mathrm{Pa} ; R^{*}$ is the equivalent contact radius, $\mathrm{m}$. 
The equivalent contact radius $R^{*}$ and the equivalent elastic modulus $E^{*}$ are defined as Equations (3) and (4):

$$
\begin{gathered}
\frac{1}{E^{*}}=\frac{1-V_{1}^{2}}{E_{1}}+\frac{1-V_{2}^{2}}{E_{2}}, \\
\frac{1}{R^{*}}=\frac{1}{R_{1}}+\frac{1}{R_{2}} .
\end{gathered}
$$

The expression of the linear cohesion model normal cohesion force $F$ is as follow Equation (5):

$$
F=K A,
$$

where, $A$ is the contact area, $\mathrm{m}^{2} ; \mathrm{K}$ is the energy density, $\mathrm{J} \cdot \mathrm{m}^{-3}$; this force is added to the conventional Hertz-Mindlin normal force.

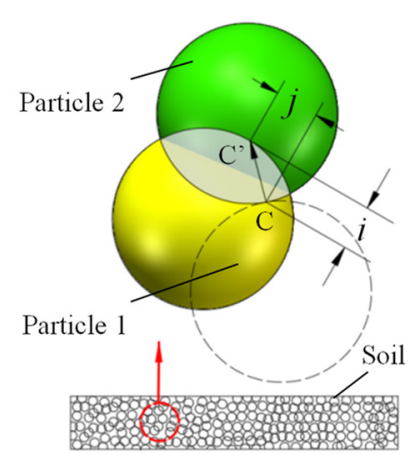

(a)

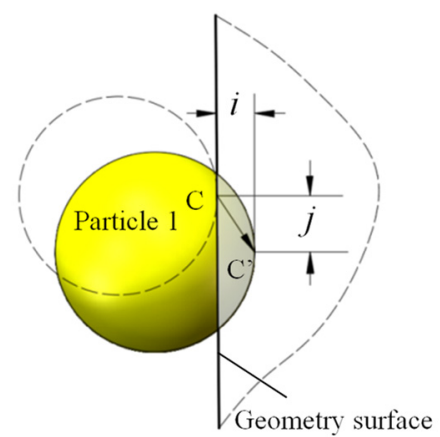

(b)

Figure 3. Contact model: (a) particle to particle; (b) particle to geometry.

\subsection{Test Method}

Design Expert software was adopted to create the test scheme for the PB test and BBD. Simulation parameters were entered into the EDEM software for simulation according to the test scheme. At the end of the simulation, the total soil adhesion mass adhering to the rotary tillage part was measured by Total Mass Sensor in EDEM software post-processing module. The measured soil adhesion masses were input into Design Expert software to screen for significance parameters. Then, BBD was carried out to obtain a regression model between the significance parameters and soil adhesion mass. The soil adhesion mass measured in the soil bin test was brought into the regression model as the target value. Multiple sets of parameter values were solved by Design Expert software optimization module, and multiple sets of parameter values were brought into EDEM for simulation to obtain the optimal parameters solution. The accuracy of the parameters was verified by comparing the relative error between the simulated soil adhesion mass in the optimal parameters solution and the actual soil bin test results.

\subsubsection{Simulation Parameters}

Wet clay soil particles are bonded to each other, and most of the structural forms are agglomerates. The size of the simulation particles was limited by the computing power of the computer, and the simulation time becomes longer with the increase of the number of particles. To shorten the simulation time, a $4 \mathrm{~mm}$ radius sphere was used as the simulation soil particle base [26,27]. In this study, based on several pre-tests and with reference to the relevant soil calibration literature, the range of contact parameters for the discrete element model was determined as shown in Table 2 [28-30]. The intrinsic parameters of material were as follows: the density, Poisson's ratio, and shear modulus of the soil particles were $1850 \mathrm{~kg} \cdot \mathrm{m}^{-3}, 0.38,1 \times 10^{6} \mathrm{~Pa}$, respectively. The density, Poisson's ratio, and shear modulus of the geometry were $7865 \mathrm{~kg} \cdot \mathrm{m}^{-3}, 0.3,7.9 \times 10^{10} \mathrm{~Pa}$, respectively. The acceleration of gravity, simulation time step, and simulation time were $9.81 \mathrm{~m} \cdot \mathrm{s}^{-2}, 5 \%, 3.5 \mathrm{~s}$, respectively. The save data step interval was $0.05 \mathrm{~s}$. 
Table 2. The range of simulation parameters.

\begin{tabular}{|c|c|c|c|c|c|}
\hline \multirow{2}{*}{\multicolumn{3}{|c|}{ Simulation Parameters }} & \multicolumn{3}{|c|}{ Levels } \\
\hline & & & Low Level $(-1)$ & Middle Level (0) & High Level (1) \\
\hline \multirow{2}{*}{$\begin{array}{l}\text { Material contact } \\
\text { parameters }\end{array}$} & Particle-particle & $\begin{array}{l}\text { Coefficient of restitution (A) } \\
\text { Coefficient of static friction (B) } \\
\text { Coefficient of rolling friction (C) }\end{array}$ & $\begin{array}{l}0.1 \\
0.01 \\
0.01\end{array}$ & $\begin{array}{c}0.45 \\
0.505 \\
0.21\end{array}$ & $\begin{array}{c}0.8 \\
1 \\
0.41\end{array}$ \\
\hline & Particle-geometry & $\begin{array}{l}\text { Coefficient of restitution (D) } \\
\text { Coefficient of static friction (E) } \\
\text { Coefficient of rolling friction (F) }\end{array}$ & $\begin{array}{c}0.05 \\
0.1 \\
0.05\end{array}$ & $\begin{array}{c}0.375 \\
0.6 \\
0.25\end{array}$ & $\begin{array}{l}0.7 \\
1.1 \\
0.45\end{array}$ \\
\hline $\begin{array}{l}\text { Contact model } \\
\text { parameters }\end{array}$ & $\begin{array}{l}\text { Particle-particle } \\
\text { Particle-geometry }\end{array}$ & $\begin{array}{l}\text { JKR surface energy }(\mathrm{G}) \\
\text { Energy density }(\mathrm{H})\end{array}$ & $\begin{array}{c}50 \\
4 \times 10^{5}\end{array}$ & $\begin{array}{c}75 \\
5 \times 10^{5}\end{array}$ & $\begin{array}{c}100 \\
6 \times 10^{5}\end{array}$ \\
\hline
\end{tabular}

\subsubsection{Simulation Test Design}

Referring to the test design method of the study by Xia et al. and Mohanty et al. [31,32], the PB test was conducted to obtain the simulation parameters that had a significant effect on the response value, using the soil adhesion mass of the rotary tillage part as the response value. The maximum value, middle value, and minimum value of the simulation parameters was taken as the high level, middle level, and low level of the test (Table 2). The high level and low level of the simulation parameters were represented in the form of code 1 and -1 , respectively, and the middle level was represented as code 0 . In this study, the 11-factor table of Design Expert software was used for design of PB test. The simulation parameters (code $\mathrm{A} \sim \mathrm{H}$ ) were used as real variables, and the other three parameters (code $\mathrm{J} \sim \mathrm{K}$ ) were used as virtual variables for error analysis. The values of virtual variables were represented by encoding 1 and -1 .

Based on the results of the PB test, the significant simulation parameters were selected for the BBD. The middle value of non-significant simulation parameters was chosen for simulation. The central horizontal group was repeated five times. A total of 17 groups of simulation tests on the soil adhesion of rotary tillage part were conducted. Finally, a regression model between soil adhesion mass and significant simulation parameters for rotary tillage was constructed. The accuracy of the simulation parameter values was verified by comparing the simulation soil adhesion mass with the soil adhesion mass of the actual test.

\subsection{Simulation Model}

As shown in Figure 4, the simulation model was built in the EDEM software. The size of the soil bin model was $1200 \mathrm{~mm} \times 500 \mathrm{~mm} \times 200 \mathrm{~mm}$ (length $\times$ width $\times$ height). The rotating center of the rotary tillage part was $250 \mathrm{~mm}$ from the soil surface. The vertical entry speed was $775 \mathrm{~mm} \cdot \mathrm{s}^{-1}(0 \sim 0.2 \mathrm{~s}$, tillage depth $150 \mathrm{~mm})$, the forward speed was $600 \mathrm{~mm} \cdot \mathrm{s}^{-1}$ $(0.2 \sim 1.2 \mathrm{~s})$, the rising speed of was $2200 \mathrm{~mm} \cdot \mathrm{s}^{-1}(1.2 \sim 1.4 \mathrm{~s})$, and the rotating speed was $150 \mathrm{rpm}(0 \sim 2.2 \mathrm{~s})$. To ensure that the particles were relatively stationary, the total simulation time was set to $3.5 \mathrm{~s}$.

As shown in Figure 4a, in order to clarify the adhesion process of the soil, the soil bin was divided equally into two parts, left and right, with a central surface. The left part was equally divided into nine soil zones from S1 to S9, where S1, S2, S3 is the upper soil layer, S4, S5, S6 is the middle soil layer, and S7, S8, S9 is the lower soil layer. As shown in Figure $4 \mathrm{~b}$, the rotary tillage part tilled at a distance of $365 \mathrm{~mm}$ in S1, S4, S7, $400 \mathrm{~mm}$ in S2, $\mathrm{S} 5, \mathrm{~S} 8$, and $325 \mathrm{~mm}$ in S3, S6, S9. The simulation data from 0 to the end of $3.5 \mathrm{~s}$ was saved using the post-processing module of EDEM software. After simulating the complete data acquisition cycle, the resultant data was processed. 


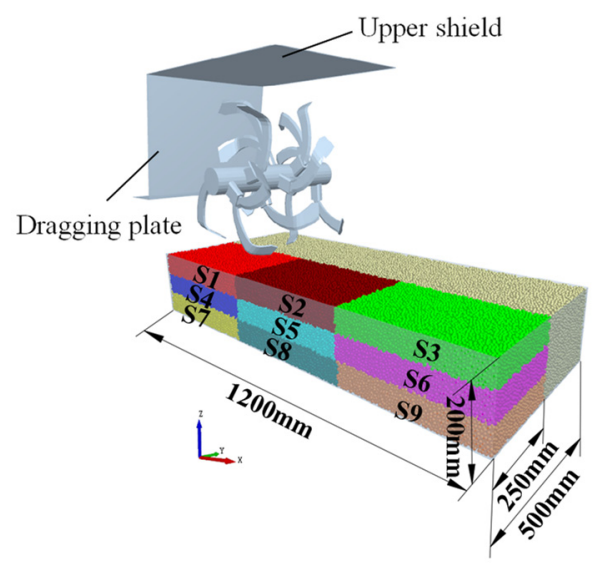

(a)

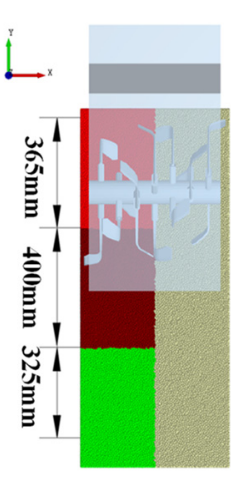

(b)

Figure 4. Simulation model: (a) soil bin model (b) tillage distance.

\section{Results and Analysis}

\subsection{Simulation Test Results}

\subsubsection{Analysis of PB Test Results}

In this study, the PB test was used to investigate the effect of simulation parameters on the soil adhesion mass. Table 3 shows the PB test scheme and the soil adhesion mass obtained after inputting the simulation parameters into the EDEM software for simulation according to the test scheme.

Table 3. Results of Plackett-Burman test.

\begin{tabular}{cccccccccccccc}
\hline \multirow{2}{*}{ Test Serial Number } & \multicolumn{10}{c}{ Parameter Notations } & Soil Adhesion Mass Q/kg \\
\cline { 2 - 10 } & A & B & C & D & E & F & G & H & I & J & K & \\
\hline 1 & 1 & 1 & -1 & 1 & 1 & 1 & -1 & -1 & -1 & 1 & -1 & 3.08929 \\
2 & -1 & 1 & 1 & -1 & 1 & 1 & 1 & -1 & -1 & -1 & 1 & 3.16071 \\
3 & 1 & -1 & 1 & 1 & -1 & 1 & 1 & 1 & -1 & -1 & -1 & 2.57697 \\
4 & -1 & 1 & -1 & 1 & 1 & -1 & 1 & 1 & 1 & -1 & -1 & 4.26519 \\
5 & -1 & -1 & 1 & -1 & 1 & 1 & -1 & 1 & 1 & 1 & -1 & 1.89305 \\
6 & -1 & -1 & -1 & 1 & -1 & 1 & 1 & -1 & 1 & 1 & 1 & 4.80082 \\
7 & 1 & -1 & -1 & -1 & 1 & -1 & 1 & 1 & -1 & 1 & 1 & 3.28965 \\
1 & 1 & 1 & -1 & -1 & -1 & 1 & -1 & 1 & 1 & -1 & 1 & 3.44142 \\
1 & 1 & 1 & 1 & -1 & -1 & -1 & 1 & -1 & 1 & 1 & -1 & 3.81288 \\
& -1 & 1 & 1 & 1 & -1 & -1 & -1 & 1 & -1 & 1 & 1 & 3.45382 \\
\end{tabular}

The model in Table 4 had the coefficient of determination $\left(R^{2}\right)$ of 0.9678 and adjustment coefficient of determination $\left(R^{2}\right.$ adj $)$ of 0.8818 . This indicated that the model could be used to explain the effects of the factors on the response values. The $C V$ of the model was $8.43 \%$ and the adequate precision was 11.294. In summary, this showed that the test results had greater reliability. The model was evaluated adequately to screen the parameters that had a significant effect on soil adhesion mass. Significance of the parameters up to $p<0.05$ indicated that the confidence level of the parameters was higher than $95 \%$, which was considered statistically significant. Such parameters could be included in subsequent BBD. 
Table 4. Analysis of significance parameters in Plackett-Burman test.

\begin{tabular}{cccccc}
\hline Parameters & Effect & Sum of Squares & Contribution/\% & $\boldsymbol{p}$-Value & Significance Ranking \\
\hline A & -0.48 & 0.69 & 9.47 & 0.0592 & 4 \\
B & 0.42 & 0.54 & 7.33 & 0.0797 & 5 \\
C & -0.92 & 2.53 & 34.57 & $0.0109 *$ & 1 \\
D & 0.18 & 0.095 & 1.30 & 0.3516 & 8 \\
E & -0.65 & 1.27 & 17.39 & $0.0276 *$ & 7 \\
F & -0.33 & 0.33 & 4.49 & 0.1334 & 3 \\
G & 0.65 & 1.27 & 17.34 & $0.0277 *$ & 6 \\
H & -0.35 & 0.36 & 4.88 & 0.1228 & \\
\multicolumn{7}{c}{$=0.9678, \mathrm{R}^{2}$ adj $=0.8818, C V=8.43 \%$, adequate precision $=11.294$} \\
\hline
\end{tabular}

Note: ${ }^{*}$ indicated significance at 0.05 level.

According to the test results, we can not only see the positive and negative effect of factors, but also the significance ranking of factors directly. The parameter significance was ranked in the order from largest to smallest as the particle-particle coefficient of rolling friction, particle-geometry coefficient of static friction, particle-particle JKR surface energy, particle-particle coefficient of restitution, particle-particle coefficient of static friction, particle-geometry energy density, particle-geometry coefficient of rolling friction, and particle-geometry coefficient of restitution. The simulation parameters that had a significant $(p<0.05)$ effect on the soil adhesion mass included particle-particle coefficient of rolling friction, particle-geometry coefficient of static friction, and particle-particle JKR surface energy.

\subsubsection{Analysis of BBD Results}

The BBD scheme and simulation results were shown in Table 5.

Table 5. Results of Box-Behnken Design test simulation.

\begin{tabular}{ccccc}
\hline $\begin{array}{c}\text { Test } \\
\text { Serial } \\
\text { Number }\end{array}$ & $\begin{array}{c}\text { Particle-Particle } \\
\text { Coefficient of } \\
\left.\text { Rolling Friction } \boldsymbol{( X}_{\mathbf{1}}\right)\end{array}$ & $\begin{array}{c}\text { Particle-Geometry } \\
\text { Coefficient of Static } \\
\text { Friction }\left(\boldsymbol{X}_{\mathbf{2}}\right)\end{array}$ & $\begin{array}{c}\text { Particle-Particle } \\
\text { JKR Surface } \\
\text { Energy }\left(\boldsymbol{X}_{\mathbf{3}}\right)\end{array}$ & $\begin{array}{c}\text { Soil Adhesion } \\
\text { Mass } \boldsymbol{Q} / \mathbf{k g}\end{array}$ \\
\hline 1 & -1 & -1 & 0 & 4.18287 \\
2 & 1 & -1 & 0 & 3.83967 \\
3 & -1 & 1 & 0 & 4.22254 \\
4 & 1 & 1 & 0 & 3.56838 \\
5 & -1 & 0 & -1 & 3.17658 \\
6 & 1 & 0 & -1 & 2.59036 \\
7 & -1 & 0 & 1 & 4.34951 \\
8 & 1 & 0 & 1 & 3.50291 \\
9 & 0 & -1 & -1 & 3.44985 \\
10 & 0 & 1 & -1 & 2.80660 \\
11 & 0 & 1 & 1 & 4.49234 \\
12 & 0 & 0 & 0 & 3.90811 \\
13 & 0 & 0 & 0 & 3.16467 \\
14 & 0 & 0 & 0 & 3.20683 \\
15 & 0 & 0 & 0 & 3.35562 \\
16 & 0 & 0 & 0 & 3.35264 \\
17 & 0 & 0.21725 \\
\hline
\end{tabular}

The quadratic regression model for the soil adhesion mass $Q$ and the three significant simulation parameters based on the test results is shown in Equation (6).

$$
\begin{gathered}
Q=3.26-0.3 X_{1}-0.18 X_{2}+0.53 X_{3}-0.078 X_{1} X_{2}-0.065 X_{1} X_{3} \\
+0.015 X_{2} X_{3}+0.22 X_{1}^{2}+0.48 X_{2}^{2}-0.072 X_{3}^{2}
\end{gathered}
$$

where $Q$ is the soil adhesion mass, $\mathrm{kg} ; X_{1}$ is the particle-particle coefficient of rolling friction; $X_{2}$ is the particle-geometry coefficient of static friction; $X_{3}$ particle-particle JKR surface energy, $\mathrm{J} \cdot \mathrm{m}^{-2}$.

The regression model ANOVA results were shown in Table 6. The coefficient of determination $\left(R^{2}\right)$ was 0.9616 , and the adjustment coefficient of determination $\left(R^{2}\right.$ adj $)$ was 
0.9121. These values indicated that the fitting degree of the regression equation was good. The regression model could be used to replace the real test in analyzing the result. The model $p$-value was 0.0004 , which showed a highly significant $(p<0.01)$ relationship between the model response value (soil adhesion mass) and the independent variable (simulation parameters). The adequate precision reached 14.037 and the coefficient of variation $(\mathrm{CV})$ was $4.51 \%$, which manifested that the model had good precision and credibility.

Table 6. ANOVA of quadratic polynomial model of Box-Behnken Design test.

\begin{tabular}{ccccc}
\hline $\begin{array}{c}\text { Source of } \\
\text { Variation }\end{array}$ & Sum of Square & $\begin{array}{c}\text { Degrees of } \\
\text { Freedom }\end{array}$ & Mean Square & $p$-Value \\
\hline Model & 4.49 & 9 & 0.50 & $0.0004^{* *}$ \\
$X_{1}$ & 0.74 & 1 & 0.74 & $0.0010^{* *}$ \\
$X_{2}$ & 0.27 & 1 & 0.27 & $0.0146^{* *}$ \\
$X_{3}$ & 2.24 & 1 & 2.24 & $<0.0001^{* *}$ \\
$X_{1 \times 2}$ & 0.024 & 1 & 0.024 & 0.3640 \\
$X_{1 \times 3}$ & 0.017 & 1 & 0.017 & 0.4431 \\
$X_{2}{ }^{3}$ & $8.71 \times 10^{-4}$ & 1 & $8.71 \times 10^{-4}$ & 0.8590 \\
$X_{1}^{2}$ & 0.20 & 1 & 0.20 & $0.0271^{*}$ \\
$X_{2}^{2}$ & 0.96 & 1 & 0.96 & $0.0005^{* *}$ \\
$X_{3}^{2}$ & 0.022 & 1 & 0.022 & 0.3879 \\
Residual & 0.18 & 7 & 0.026 & - \\
Lack of fit & 0.15 & 3 & 0.049 & 0.0541 \\
Pure error & 0.031 & 4 & $7.87 \times 10^{-3}$ & - \\
Total & 4.67 & 16 & - & -
\end{tabular}

Note: ${ }^{* *}$ and * indicated significance at 0.01 and 0.05 levels, respectively.

\subsubsection{Interaction Effects of the Regression Model}

The data was processed to obtain the effects of the interaction between the particleparticle coefficient of rolling friction, particle-geometry coefficient of static friction, and particle-particle JKR surface energy on the soil adhesion mass. Figure 5a shows the response surface for the interaction of particle-geometry coefficient of static friction and particleparticle coefficient of rolling friction when the JKR surface energy is located at the central level $\left(75 \mathrm{~J} \cdot \mathrm{m}^{-2}\right)$. As the particle-geometry coefficient of static friction increased, the soil adhesion mass first decreased and then increased. Soil adhesion mass decreased with the increase of particle-particle rolling friction coefficient, and the decrease was small and flat. Among the interactions of particle-geometry coefficient of static friction and particle-particle coefficient of rolling friction, the particle-geometry coefficient of static friction had a greater influence on the interaction. As shown in Figure $5 b$, the particlegeometry coefficient of static friction is located at the central level (0.6). The soil adhesion mass increased with the increase of JKR surface energy, with a larger increase. The soil adhesion mass decreased with increasing particle-particle coefficient of rolling friction, and the decrease was small and flat. As shown in Figure $5 c$, the particle-particle coefficient of rolling friction is located at the central level (0.21). An increase in JKR surface energy contributed to an increase in soil adhesion mass that was significant. As the particlegeometry coefficient of static friction increases, the soil adhesion mass decreased and then increased, and the decrease was greater than the increase. In Figure 5b,c, it can be found that the JKR surface energy had a large influence on the interaction. In summary, the particle-particle JKR surface energy was positively correlated with the soil adhesion mass, and the particle-particle static friction coefficient and particle-geometry static friction coefficient were negatively correlated with the soil adhesion mass. 


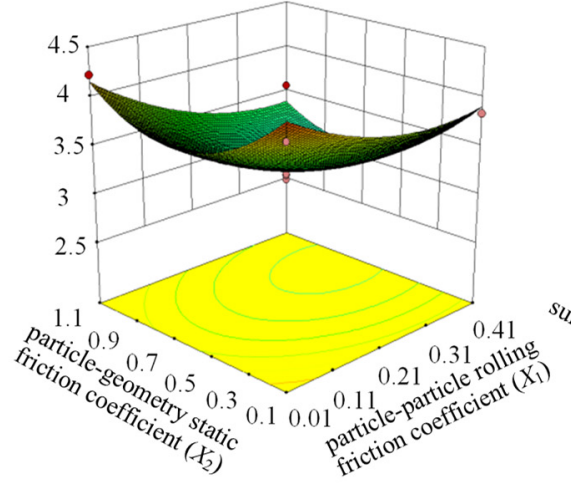

(a)

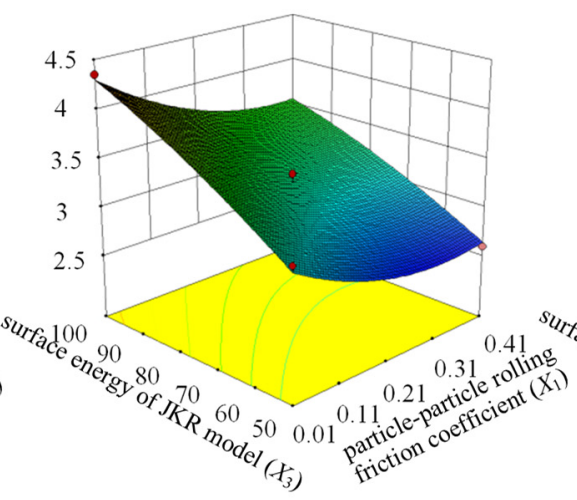

(b)

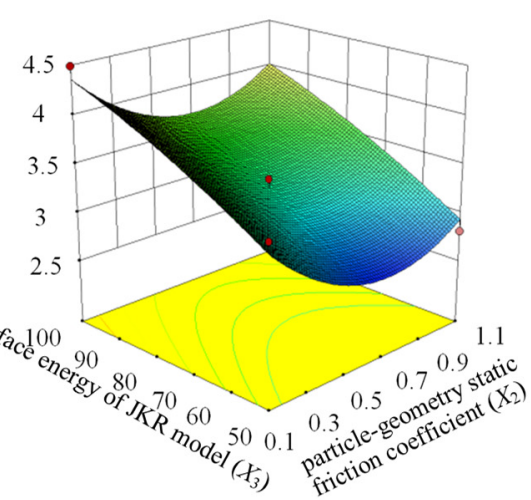

(c)

Figure 5. Interaction between parameters affecting soil adhesion mass: (a) interaction between $X_{1}$ and $X_{2}$; (b) interaction between $X_{1}$ and $X_{3} ;(\mathbf{c})$ interaction between $X_{2}$ and $X_{3}$.

\subsubsection{Determination of Optimal Simulation Parameters}

The average value of actual soil adhesion mass measured in the soil bin tests was $3.23205 \mathrm{~kg}$. The actual measured soil adhesion mass was the target value brought into the regression model (Equation (6)) to solve the simulation parameters. Multiple sets of simulation parameter solutions can be obtained, which were input into EDEM for rotary tillage adhesion simulation tests. The optimal set of solutions closest to the actual measured soil adhesion mass was obtained: particle-particle coefficient of rolling friction of 0.09 , particle-geometry coefficient of static friction of 0.81 ; and particle-particle JKR surface energy of $61.55 \mathrm{~J} \cdot \mathrm{m}^{-2}$.

As shown in Figure 6, the actual test result was compared with the simulation test result under the optimal combination. The simulation test measured a soil adhesion mass of $3.29164 \mathrm{~kg}$, which was a relative error of $1.84 \%$ compared to the average value of the actual soil adhesion mass (the average value of the actual soil adhesion mass was the standard value). The result showed that it was feasible to apply the combination of the PB test and BBD to obtain the simulation parameter values.

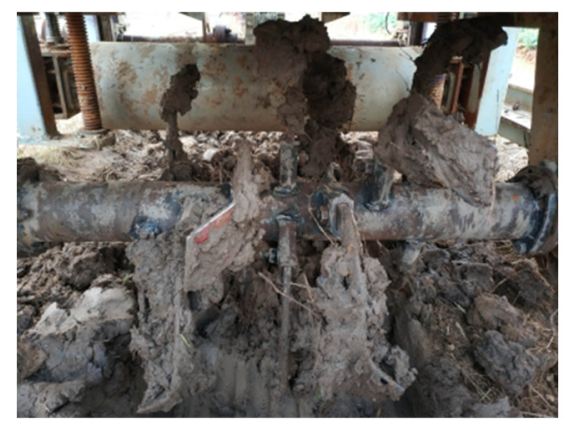

(a)

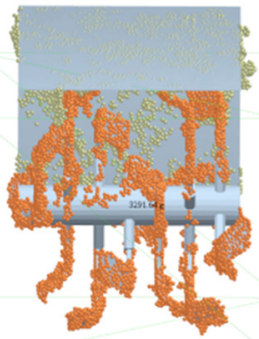

(b)

Figure 6. Results of soil adhesion test: (a) actual test (b) simulation test.

\subsection{Analysis of Soil Adhesion Process}

\subsubsection{The Process of Soil Adhering to Rotary Tillage Part}

As shown in Figure 7, the rotary tillage part entered the soil vertically at $0.2 \mathrm{~s}$. The sidelong section of the rotary blade touched the soil first and cut it, so that the soil could be found adhering to the sidelong section. Soil was thrown back by the rotary blade and came into touch with the dragging plate. At $0.7 \mathrm{~s}$, the high cohesion between soil particles caused the thrown soil to be agglomerates, resulting in soil congestion between the rotary tillage part and the dragging plate. Part of the soil was thrown into an untilled area in front of the rotary tillage part. The soil formed an adhesion layer that was not easily dislodged from 
the sidelong section and moved with the rotary blade. At $1.2 \mathrm{~s}$, the rotary blade repeatedly cut the congested soil at the back causing some soil to move up, which resulted in some of the soil adhering to the upper shield. In the forward process, a small amount of soil adhering to the rotor shaft. The reason for this was that a small amount of soil touched the rotor shaft when soil fell from the air after being thrown by the rotary blade. In addition, some of the soil was thrown into an untilled area in front of the rotary tillage part causing soil accumulation and an uneven tillage surface, which lead to some soil easier adhering to the rotor shaft in the process of tillage. At $1.4 \mathrm{~s}$, the rotary tillage part came out of the soil and kept rotating. The congested soil between the rotary tillage part and the dragging plate fell off and the soil was dislodged between the blade holder. The rotary tillage part stopped at $2.2 \mathrm{~s}$. As shown in Figure 7e, a small amount of soil was separated from the rotary blade by inertia after the rotary tillage part stopping. The simulation quit at $3.5 \mathrm{~s}$ and the particles were stationary. It could be seen that soil adhesion was generated in the rotary blade, rotor shaft, dragging plate, and the upper shield.

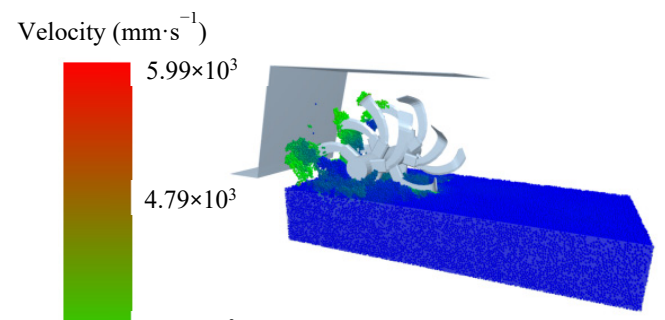

(a). $0.2 \mathrm{~s}$

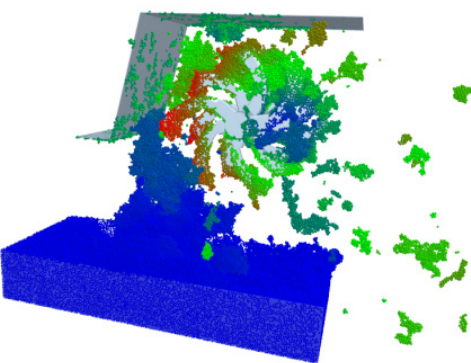

(d). $1.4 \mathrm{~s}$

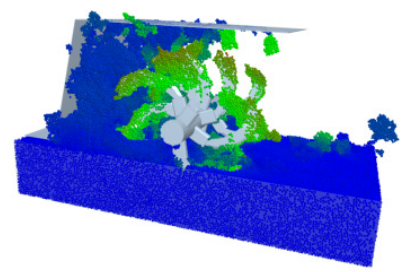

(b). $0.7 \mathrm{~s}$

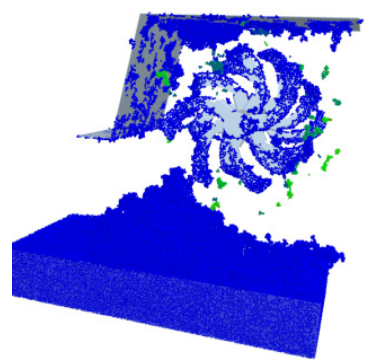

(e). $2.25 \mathrm{~s}$

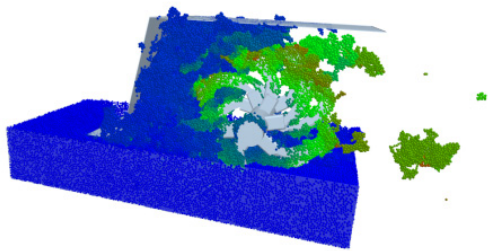

(c). $1.2 \mathrm{~s}$

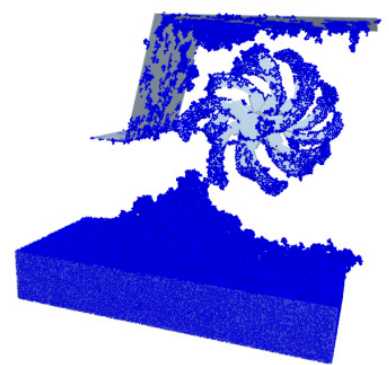

(f). $3.5 \mathrm{~s}$

Figure 7. The process of rotary tillage. (a) $0.2 \mathrm{~s} \mathrm{(b)} 0.7 \mathrm{~s} \mathrm{(c)} 1.2 \mathrm{~s}$ (d) $1.4 \mathrm{~s} \mathrm{(e)} 2.25 \mathrm{~s} \mathrm{(f)} 3.5 \mathrm{~s}$.

\subsubsection{Rotary Tillage Unit Soil Particles Distribution}

In order to observe the distribution state of soil particles inside a rotary tillage unit during the rotary tillage process, a Geometry Bin in EDEM post-processing module was created at $0.2 \mathrm{~s}, 0.7 \mathrm{~s}$, and $1.2 \mathrm{~s}$ (Length $\times$ width $\times$ height was $500 \mathrm{~mm} \times 60 \mathrm{~mm} \times 800 \mathrm{~mm}$ ) The coordinates of the soil particles within the Geometry Bin were derived to analyze the location of the soil particle distribution.

As shown in Figure 8, particle color from purple to red represents particle height from low to high. The number of particles was intensive at the sidelong section of the rotary blade, while relatively less soil adhered to the lengthwise section of the rotary blade, which indicated that the soil adhesion on the rotary blade was mainly concentrated in the sidelong section. At 0.2 to $1.2 \mathrm{~s}$, the soil present in a rotary tillage unit was composed of three parts: soil in the soil bin, soil adhering to the rotary tillage part, and the soil that was thrown in the air. A space with relatively little soil appeared in the horizontal space above the center line of the rotor shaft. As shown in Figure 8c, the motion of the rotary blade included rotation and forward movement, so the motion trajectory of the rotary blade during the rotary tillage was the trochoid. Therefore, the rotary blade lifted the soil at the bottom in front of the rotor shaft, and the contact between the rotor shaft and the lifted soil caused a small amount of soil to adhere to the rotor shaft. The rotary blade caused little disturbance to the untilled area and the lower soil layer. 


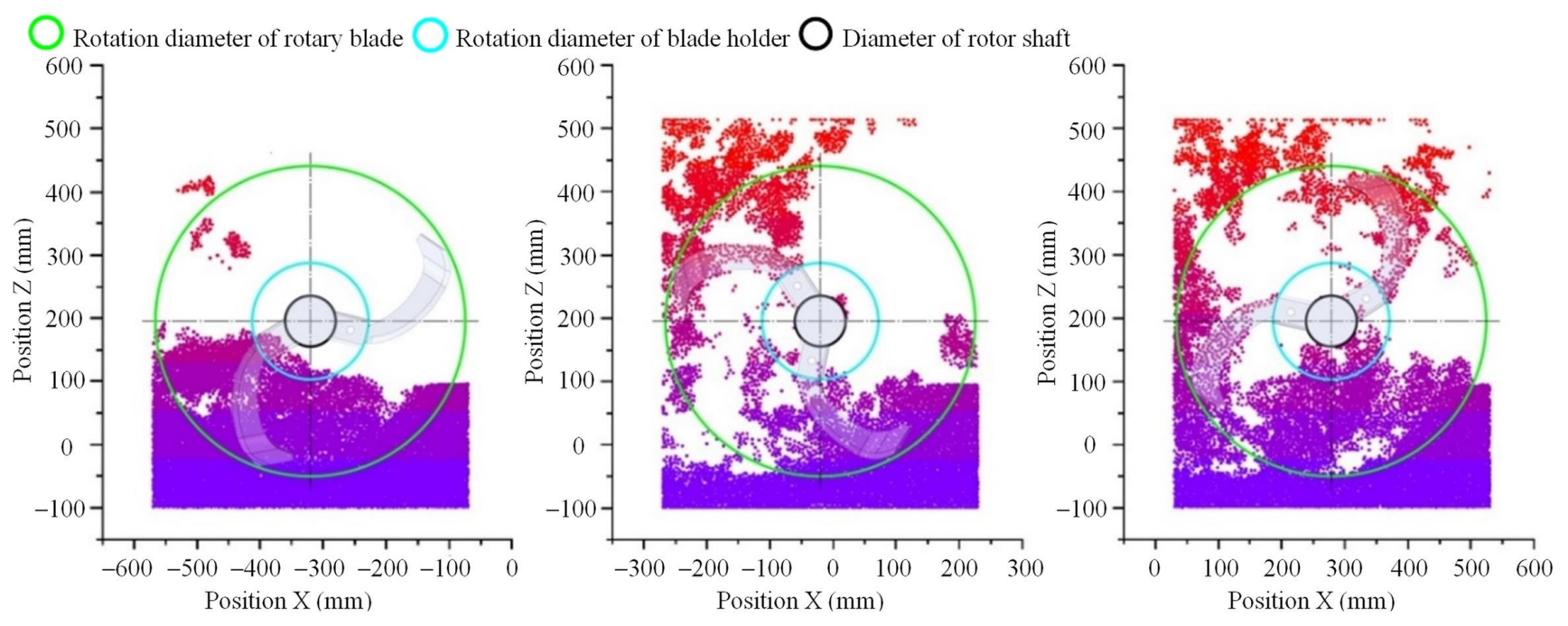

Figure 8. Rotary tillage unit soil particles distribution: (a) $0.2 \mathrm{~s} \mathrm{(b)} 0.7 \mathrm{~s} \mathrm{(c)} 1.2 \mathrm{~s}$.

\subsubsection{Soil Particles Adhesion in Different Soil Zones}

Figure 9 shows the number of adhesion soil particles to the rotary tillage part for each soil zone at the end of the $3.5 \mathrm{~s}$ simulation. The presence of soil particles from each soil zone on the rotary tillage part at the end of the simulation, which suggested that soil adhesion was a continuous process that occurred during the rotary tillage. Soil particles adhering to the rotary tillage part were dislodged by the force. When the rotary tillage part cut and squeezed the soil again, the rotary tillage part was again adhering by new soil particles. The number of soil particles adhering to rotary tillage part in the upper soil layer was $\mathrm{S} 1+\mathrm{S} 2+\mathrm{S} 3=2605$, and the number of soil particles adhering to rotary tillage part in the middle soil layer was $\mathrm{S} 4+\mathrm{S} 5+\mathrm{S} 6=771$, and the number of soil particles adhering to rotary tillage part in the lower soil layer was $\mathrm{S} 7+\mathrm{S} 8+\mathrm{S} 9=49$. Comparing the number of adhesion particles in the middle and lower soil layers, the number of adhesion particles in the upper soil layer was the highest during the rotary tillage. Rotary blade cutting soil included three stages: entry soil stage, exit soil stage, and return stage. In the exit soil stage, the rotary blade passed through the lower soil layer, the middle soil layer, and the upper soil layer in turn. Soil particles adhering to the rotary blade were subject to friction and cohesion between the particles, which made the lower and middle soil layers particles adhering to the rotary blade gradually fall off. As a result, the number of adhered particles in the middle and lower soil layers was not as much as that in the upper soil layer. The main reason for the number of adhesion particles in the lower soil layer being less than the middle soil layer was that the tillage depth was $150 \mathrm{~mm}$, and the contact between the rotary tillage part and the lower soil layer was less.

The number of particles adhering to rotary tillage part was 1107 in the S1, S4, S7 zones, 1845 in the S2, S5, S8 zones, and 473 in the S3, S6, S9 zones. The highest number of particles adhering to the rotary tillage part in the S2, S5, S8 zones due to the longest operating distances in the S2, S4, S6 zones (Figure 4a). Combined with Figure 10, it can be obtained that the number of particles in the upper soil layer had maximum variation from 0 to $3.5 \mathrm{~s}$, followed by the number of soil particles in the middle layer, and the minimum change in the number of soil particles in the lower layer. This also shows that the small disturbance of the untilled area and the lower soil layer found in Figure 8c was correct. 


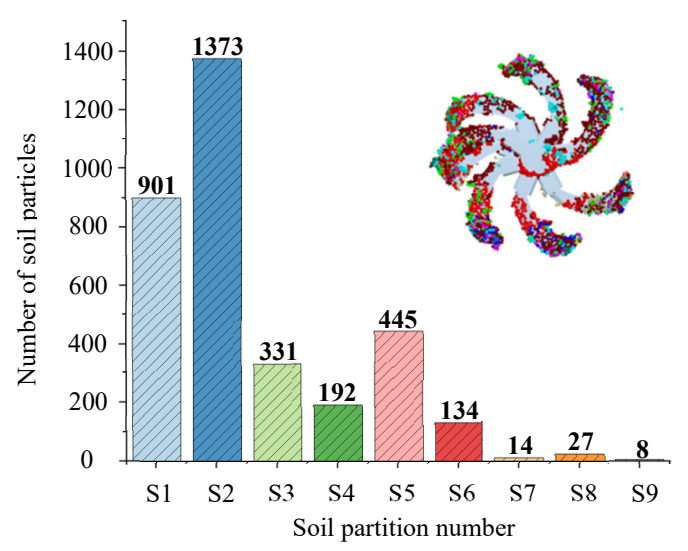

Figure 9. The number of soil particles adhering to the rotary tillage part.

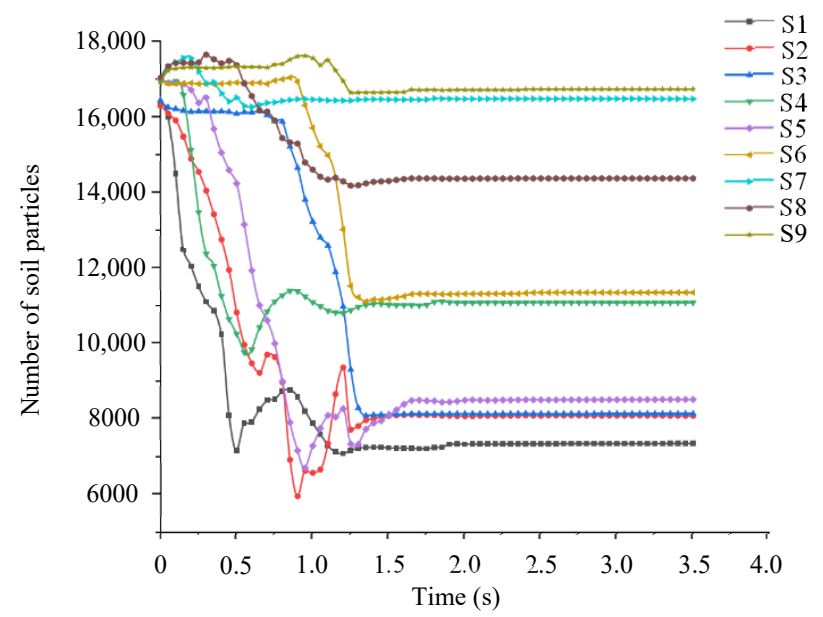

Figure 10. Variation of particle number in different zones during rotary tillage.

\section{Discussion}

\subsection{Effect of Soil Moisture conTent and Straw on Soil Adhesion Mass}

In this study, simulation parameters were determined by combining a simulation test with an actual physical test. However, there was a relative error in the soil adhesion mass between the simulation and actual tests. Because different tillage patterns, soil textures and agronomic activities result in different soil properties, such as different soil structure, bulk density, moisture content $[33,34]$. The wet clay soil strength and deformation behavior was significantly affected by changing moisture content. The moisture content varies within a certain range, which makes the soil more plastic. High plasticity clay has high cohesion and can withstand large plastic deformation without dispersion. The adhesion will increase when the moisture content increases within a certain range [35]. Simulation results also revealed that the greater the JKR surface energy, the greater the cohesion between the particles and the greater the adhesion mass of the soil particles. Particles and particles were not easily dispersed, and the soil thrown out by the rotary blade was mostly agglomerated. In the field operations, even in the same tillage area, the moisture content had significant variation from spot to spot, which will have a significant impact on the soil adhesion mass of the machine.

The soil bin test found that the soil adhesion was mainly concentrated in the sidelong section of the rotary blade, where the rotary blade was squeezed and cut with soil and straw. An adhesion layer of soil-straw mixture was formed on the sidelong section, which was wrapped around the sidelong section and not easily dislodged. The adhesion layer cut the soil together with the rotary blade. It was basically consistent with the results of the simulation in this paper that soil particles were mainly adhering to the sidelong section. 
The length and amount of straw in the soil affects the soil porosity and straw increases the aggregation of the soil at the interface, resulting in the creation of large soil aggregates [36]. The uneven spatial distribution of straw on the ground cover will lead to differences in the cutting effect of the rotary blade on the straw, producing a phenomenon of varying lengths, and relevant studies have shown that shorter straw is more likely to mix with the soil [37]. After mixing straw with soil, an uneven vertical distribution of straw in the shallow soil occurs, as soil mixed with straw loosens soil to reduce soil bulk density, and increases porosity and moisture content [38]. Therefore, straw significantly affects the soil adhesion mass.

\subsection{Measures to Reduce Soil Adhesion Mass of Rotary Tillage Part}

Combined with the simulation test, it was concluded that the upper soil particles adhere more to the rotary tillage part. Therefore, after the field crops are harvested, the sunshine duration can be increased appropriately according to the growth cycle of the next crop. In this way, the moisture content of the upper layer of soil is reduced, thus reducing the adhesion between the rotary tillage part and the soil. The rototiller dragging plate can be removed to increase the mobility of the soil when working in wet clay soil, which can avoid the congestion caused by the soil accumulating between the rotary tillage part and the dragging plate. Increasing the rotational speed and forward speed can reduce the contact time between the rotary blade and the soil. By reducing the contact time with the soil, the soil particles and the water in the soil are prevented from being redistributed, and the continuous water film between the soil and the rotary blade is further prevented from increasing the contact area to form an interface adhesion. Soil adhesion of the rotary tillage part is mainly concentrated in the sidelong section of rotary tillage part, which can be covered with a layer of anti-adhesive nano-coating only in the sidelong section of rotary tillage part to reduce soil adhesion.

\section{Conclusions}

(1) It was feasible to simulate the rotary tillage of wet clay soil by using JKR contact model for particle-particle and Linear Cohesion contact model for particle-geometry in EDEM software.

(2) According to the Plackett-Burman (PB) test, particle-particle coefficient of rolling friction, particle-geometry coefficient of static friction, and particle-particle JKR surface energy were determined to have a significant effect on soil adhesion mass, and with decreasing significance in that order. Regression model between the three significant parameters and soil adhesion mass was established by Box-Behnken design (BBD) response surface test. An optimal combination of parameters was obtained by solving the regression model. The result was that particle-particle coefficient of rolling friction was 0.09 , particlegeometry coefficient of static friction was 0.81 ; and particle-particle JKR surface energy was $61.55 \mathrm{~J} \cdot \mathrm{m}^{-2}$. The relative error between the simulation test and the actual test was $1.84 \%$.

(3) Analysis of the soil adhesion process revealed that soil adhesion was mainly concentrated in the sidelong section of rotary blade during the operation. The soil that was thrown out was mostly agglomerated. Soil adhesion was a continuous process that occurred during the rotary tillage, and the number of adhesion particles in the upper soil layer was the highest during the rotary tillage. The longer distance the rotary tillage part was operated in the soil, the more soil particles would adhere to it.

Author Contributions: Conceptualization, J.C.; methodology, K.Z.; validation, G.L., L.J. and D.L.; investigation, D.L. and L.J.; resources, J.X.; writing—original draft preparation J.C.; writing—review and editing, K.Z. and J.X.; supervision, G.L.; project administration, J.X.; funding acquisition, K.Z. All authors have read and agreed to the published version of the manuscript.

Funding: This study was financially supported by a program of China's National Natural Science Foundation Project (Grant No. 31901412), Natural Science Foundation Project of Hubei Province 
(Grant No. 2019CFB130) and Special Fund Project of Basic Scientific Research Business Cost of Central University (2662018QD033).

Institutional Review Board Statement: Not applicable.

Informed Consent Statement: Not applicable.

Data Availability Statement: Data sharing not applicable.

Acknowledgments: The authors would like to thank Bo Liu and Shuai Zhang for their help in this work.

Conflicts of Interest: The authors declare no conflict of interest.

\section{References}

1. Mitchell, J.P.; Carter, L.M.; Reicosky, D.C.; Shrestha, A.; Pettygrove, G.S.; Klonsky, K.M.; Marcum, D.B.; Chessman, D.; Roy, R.; Hogan, P.; et al. A history of tillage in California's Central Valley. Soil Tillage Res. 2016, 157, 52-64. [CrossRef]

2. Yang, H.; Feng, J.; Zhai, S.; Dai, Y.; Xu, M.; Wu, J.; Shen, M.; Bian, X.; Koide, R.T.; Liu, J. Long-term ditch-buried straw return alters soil water potential, temperature, and microbial communities in a rice-wheat rotation system. Soil Tillage Res. 2016, 163, 21-31. [CrossRef]

3. Chen, Z.; Li, P.; Jiang, S.; Chen, H.; Wang, J.; Cao, C. Evaluation of resource and energy utilization, environmental and eco-nomic benefits of rice water-saving irrigation technologies in a rice-wheat rotation system. Sci. Total Environ. 2021, 757, 143748. [CrossRef]

4. Jiang, Q.; Cao, M.; Wang, Y.; Wang, J.; He, Z. Quantification of the soil stiffness constants using physical properties of paddy soils in Yangtze Delta Plain, China. Biosyst. Eng. 2020, 200, 89-100. [CrossRef]

5. Yi, Q.; Liang, B.; Nan, Q.; Wang, H.; Zhang, W.; Wu, W. Temporal physicochemical changes and transformation of biochar in a rice paddy: Insights from a 9-year field experiment. Sci. Total Environ. 2020, 721, 137670. [CrossRef] [PubMed]

6. Soni, P.; Salokhe, V.M.; Nakashima, H. Modification of a mouldboard plough surface using arrays of polyethylene protuberances. J. Terramech. 2007, 44, 411-422. [CrossRef]

7. Ren, L.; Cong, Q.; Tong, J.; Chen, B. Reducing adhesion of soil against loading shovel using bionic electro-osmosis method. J. Terramech. 2001, 38, 211-219. [CrossRef]

8. Jia, X. Theoretical analysis of the adhesion force of soil to solid materials. Biosyst. Eng. 2004, 87, 489-493. [CrossRef]

9. Massah, J.; Fard, M.R.; Aghel, H. An optimized bionic electro-osmotic soil-engaging implement for soil adhesion reduction. J. Terramech. 2021, 95, 1-6. [CrossRef]

10. Zhang, D.; Chen, Y.; Ma, Y.; Guo, L.; Sun, J.; Tong, J. Earthworm epidermal mucus: Rheological behavior reveals drag-reducing characteristics in soil. Soil Tillage Res. 2016, 158, 57-66. [CrossRef]

11. Araya, K.; Kawanishi, K. Soil failure by introducing air under pressure. Trans. ASAE 1985, 27, 1292-1298. [CrossRef]

12. Schafer, R.L.; Gill, W.R.; Reaves, C.A. Experiences with lubricated plows. Trans. ASAE 1979, 22, 7-0012. [CrossRef]

13. Bahrami, M.; Naderi-Boldaji, M.; Ghanbarian, D.; Ucgul, M.; Keller, T. DEM simulation of plate sinkage in soil: Calibration and experimental validation. Soil Tillage Res. 2020, 203, 104700. [CrossRef]

14. Asaf, Z.; Rubinstein, D.; Shmulevich, I. Determination of discrete element model parameters required for soil tillage. Soil Tillage Res. 2007, 92, 227-242. [CrossRef]

15. Ucgul, M.; Fielke, J.M.; Saunders, C. Three-dimensional discrete element modelling of tillage: Determination of a suitable contact model and parameters for a cohesionless soil. Biosyst. Eng. 2014, 121, 105-117. [CrossRef]

16. Wang, X.; Zhang, S.; Pan, H.; Zheng, Z.; Huang, Y.; Zhu, R. Effect of soil particle size on soil-subsoiler interactions using the discrete element method simulations. Biosyst. Eng. 2019, 182, 138-150. [CrossRef]

17. Sun, J.; Wang, Y.; Ma, Y.; Tong, J.; Zhang, Z. DEM simulation of bionic subsoilers (tillage depth $>40 \mathrm{~cm}$ ) with drag reduction and lower soil disturbance characteristics. Adv. Eng. Softw. 2018, 119, 30-37. [CrossRef]

18. Hang, C.; Huang, Y.; Zhu, R. Analysis of the movement behaviour of soil between subsoilers based on the discrete element method. J. Terramech. 2017, 74, 35-43. [CrossRef]

19. Ucgul, M.; Saunders, C.; Fielke, J.M. Comparison of the discrete element and finite element methods to model the interaction of soil and tool cutting edge. Biosyst. Eng. 2018, 169, 199-208. [CrossRef]

20. Matin, M.A.; Fielke, J.M.; Desbiolles, J.M.A. Torque and energy characteristics for strip-tillage cultivation when cutting furrows using three designs of rotary blade. Biosyst. Eng. 2015, 129, 329-340. [CrossRef]

21. Matin, M.A.; Hossain, M.I.; Gathala, M.K.; Timsina, J.; Krupnik, T.J. Optimal design and setting of rotary strip-tiller blades to intensify dry season cropping in Asian wet clay soil conditions. Soil Tillage Res. 2021, 207, 104854. [CrossRef] [PubMed]

22. Sun, J.; Chen, H.; Wang, Z.; Ou, Z.; Yang, Z.; Duan, J. Study on plowing performance of EDEM low-resistance animal bionic device based on red soil. Soil Tillage Res. 2020, 196, 104336. [CrossRef]

23. Zeng, R.; Li, D.; Zhu, Y.; Xia, J. Design and application of performance test bench for rotary tiller components. Trans. Chin. Soc. Agric. Mach. 2020, 51, 88-97. [CrossRef]

24. Benoit, O.; Gotteland, P. Modelling of sinkage tests in tilled soils for mobility study. Soil Tillage Res. 2005, 80, 215-231. [CrossRef] 
25. Johnson, K.L.; Kendall, K.; Roberts, A. Surface energy and the contact of elastic solids. Proc. R. Soc. A-Math. Phys. Eng. Sci. 1971, 324, 301-313. [CrossRef]

26. Wang, Y.; Zhang, Y.; Yang, Y.; Zhao, H.; Yang, C.; He, Y.; Wang, K.; Liu, D.; Xu, H. Discrete element modelling of citrus fruit stalks and its verification. Biosyst. Eng. 2020, 200, 400-414. [CrossRef]

27. Katinas, E.; Chotěborský, R.; Linda, M.; Jankauskas, V. Wear modelling of soil ripper tine in sand and sandy clay by discrete element method. Biosyst. Eng. 2019, 188, 305-319. [CrossRef]

28. Xing, J.; Zhang, R.; Wu, P.; Zhang, X.; Dong, X.; Chen, Y.; Ru, S. Parameter calibration of discrete element simulation model for latosol particles in hot areas of Hainan Province. Trans. Chin. Soc. Agric. Eng. 2020, 36, 158-166. [CrossRef]

29. Li, J.; Tong, J.; Hu, B.; Wang, H.; Mao, C.; Ma, Y. Calibration of parameters of interaction between clayey black soil with different moisture content and soil-engaging component in northeast China. Trans. Chin. Soc. Agric. Eng. 2019, 35, 130-140. [CrossRef]

30. Xiang, W.; Wu, M.; Lu, J.; Quan, W.; Ma, L.; Liu, J. Calibration of simulation physical parameters of clay loam based on soil accumulation test. Trans. Chin. Soc. Agric. Eng. 2019, 35, 116-123. [CrossRef]

31. Xia, R.; Li, B.; Wang, X.; Li, T.; Yang, Z. Measurement and calibration of the discrete element parameters of wet bulk coal. Measurement 2019, 142, 84-95. [CrossRef]

32. Mohanty, S.S.; Jena, H.M. Process optimization of butachlor bioremediation by Enterobacter cloacae using Plackett Burman design and response surface methodology. Process Saf. Environ. Protect. 2018, 119, 198-206. [CrossRef]

33. Martins, R.N.; Portes, M.F.; e Moraes, H.M.F.; Junior, M.R.F.; Rosas, J.T.F.; Junior, W.D.A.O. Influence of tillage systems on soil physical properties, spectral response and yield of the bean crop. Remote Sens. Appl. 2021, 100517. [CrossRef]

34. Zhai, L.; Wang, Z.; Song, S.; Zhang, L.; Zhang, Z.; Jia, X. Tillage practices affects the grain filling of inferior kernel of summer maize by regulating soil water content and photosynthetic capacity. Agric. Water Manag. 2021, 245, 106600. [CrossRef]

35. Stafford, J.V.; Tanner, D.W. The frictional characteristics of steel sliding on soil. Eur. J. Soil Sci. 1977, 28, 541-553. [CrossRef]

36. Yang, H.; Xu, M.; Li, Y.; Xu, C.; Zhai, S.; Liu, J. The impacts of ditch-buried straw layers on the interface soil physicochemical and microbial properties in a rice-wheat rotation system. Soil Tillage Res. 2020, 202, 104656. [CrossRef]

37. Zhou, H.; Zhang, C.; Zhang, W.; Yang, Q.; Li, D.; Liu, Z.; Xia, J. Evaluation of straw spatial distribution after straw incorporation into soil for different tillage tools. Soil Tillage Res. 2020, 196, 104440. [CrossRef]

38. Getahun, G.T.; Kätterer, T.; Munkholm, L.J.; Parvage, M.M.; Keller, T.; Rychel, K.; Kirchmann, H. Short-term effects of loosening and incorporation of straw slurry into the upper subsoil on soil physical properties and crop yield. Soil Tillage Res. 2018, 184, 62-67. [CrossRef] 